1. Фуко М. Рождение биополитики. Курс лекций, прочитанных в Коллеж де Франс в 1978-1979 учебном году / пер. с фр. А. В. Дьякова. СПб. : Наука, 2010. 448 с.

2. Тилли Ч. Принуждение, капитал и европейские государства. 990-1992 гг. / пер. с англ. Т. Б. Менской. М. : Территория будущего, 2009. 358 с.

3. Райнерт Э. С. Как богатые страны стали богатыми, и почему бедные страны остаются бедными. М. : Высшая школа экономики, 2011. 384 с.

4. Деланда М. Война в эпоху разумных машин / пер. с англ. Д. Кралечкин. Екатеринбург ; М. : Кабинетный ученый ; М. : Ин-т общегуманитар. исслед., 2014. 338 с.

5. Бурдье П. Социология социального пространства / пер. с фрр. ; отв. ред. пер. Н. А. Шматко. М. : Ин-т эксперим. социологии. СПб. : Алетейя, 2007. 288 с.

6. Фуко М. Психиатрическая власть: Курс лекций, прочитанных в Коллеж де Франс в 1973-1974 учебном году / пер. с фр. А. В. Шестакова. СПб. : Наука, 2007. 450 с.

7. Попов Д. В. Практическая идеализация в биополитике // Вестн. Ом. гос. пед. ун-та. Гуманитар. исслед. 2019. № 4 (25). С. 39-43.

8. Поланьи К. Великая трансформация: политические и экономические истоки нашего времени / пер. с англ. А. А. Васильева, С. Е. Федорова и А. П. Шурбелева ; под общ. ред. С. Е. Федорова. СПб. : Алетейя, 2002. 320 с.

9. Норт Д., Уоллис Д., Вайнгаст Б. Насилие и социальные порядки. Концептуальные рамки для интерпретации письменной истории человечества / пер. с англ. Д. Узланера, М. Маркова, Д. Раскова, А. Расковой. М. : Изд-во Ин-та Гайдара, 2011. 480 с.

УДК 111

Науч. спец. 09.00 .01

DOI: 10.36809/2309-9380-2020-29-44-47

\section{O НЕКОТОРЫХ ВАРИАНТАХ «ПРИМЕНЕНИЯ" ДИАЛЕКТИКИ}

Статья посвящена методическому аспекту диалектики, применению диалектических идей в трех существенно различных областях: в революционной идеологии, обыденной жизни и военном деле. Показано, что принципы всеобщей связи и развития реализуются в каждой из них, но различается отношение к идее противоречия.

Ключевые слова: Гегель, система, метод, противоречие, марксизм, анархизм, Древний Китай, военная теория.
10. Олсон М. Власть и процветание: Перерастая коммунистические и капиталистические диктатуры. М. : Новое издательство, 2012. 212 с.

11. Болтански Л., Кьяпелло Э. Новый дух капитализма / пер. с фрр. под общ. ред. С. Фокина. М. : Новое литературное обозрение, 2011. $976 \mathrm{c}$.

12. Пикетти Т. Капитал в XXI веке. М. : Ад Маргинем Пресc, 2015. 592 c.

13. Фишман Л. Г., Мартьянов В. С., Давыдов Д. А. Рентное общество: в тени труда, капитала и демократии. М. : Изд. дом Высшей школы экономики, 2019. 416 с.

14. Стэндинг Г. Прекариат: новый опасный класс. М. : Ад Маргинем Пресс, 2014. 328 с.

15. Харари Ю. Н. 21 урок для XXI века / пер. с англ. Ю. Гольдберг. М. : Синдбад, 2019. 440 с.

16. Матурана У., Варела Ф. Древо познания: Биологические корни человеческого понимания. 2-е изд., доп. М. : УРСС : ЛЕНАНД, 2019. 320 с.

17. Мартин Г.-П., Шуманн X. Западня глобализации: атака на процветание и демократию / пер. с нем. Г. Р. Контарева. М. : Альпина, 2001. 335 с.

18. Mbembé J.-A. Necropolitics / translated by L. Meintjes. URL: https://warwick.ac.uk/fac/arts/english/currentstudents/ postgraduate/masters/modules/postcol_theory/mbembe_ 22necropolitics22.pdf (дата обращения: 07.11.2020).

19. Канторович Э. Х. Два тела короля. Исследование по средневековой политической теологии. 2-е изд., испр. / пер. с англ. М. А. Бойцова и А. Ю. Серегиной. М. : Изд-во Ин-та Гайдара, 2015. 752 с.

(С) Попов Д. В., 2020

\title{
ON SOME VARIANTS OF "APPLICATION" OF DIALECTICS
}

The article is devoted to the methodological aspect of dialectics, the application of dialectical ideas in three essentially different areas: in revolutionary ideology, everyday life and military affairs. It is shown that the principles of universal connection and development are implemented in each of them, but the attitude to the idea of contradiction is different.

Keywords: Hegel, system, method, contradiction, Marxism, anarchism, Ancient China, military theory.

Общеизвестна одна из оценок философии Гегеля, согласно которой ей присуще противоречие между методом и системой [1, с. 279]: диалектический метод носит революционный характер, а система консервативна. Наверное, следует уточнить, что в «Логике» Гегеля диалектика вовсе не метод, а основное содержание его учения. Методом она становилась для тех, кто стремился найти в диалектике обоснование собственной деятельности, чаще всего - социально-политической направленности. Знакомство с «методологизацией» диалектики позволяет проследить варианты интерпретации гегелевских идей. 
Одной из наиболее популярных оказалась идея противоречия. В «Логике» материалом для ее выдвижения стала математика, конкретно же - дифференциальное исчисление. Ключевое понятие дифференциального исчисления производная, - внутренне противоречиво. Гегель, в отличие от некоторых математиков, признает правомерность противоречивости и разворачивает идею противоречия на основе осмысления рефрлексии, которая «есть отличительное определение самой сущности» [2, с. 192]. Оказывается, что предмет и результат реслексии тождественны и в то же время различны. Далее, разворачивается критика формальной логики, в ходе которой противоречие усматривается даже в простейших высказываниях. Приводятся некоторые примеры противоречий, знакомых каждому: полюсы магнита, владение и долг и др. Наконец, следует вывод: «Противоречие - вот что на самом деле движет миром, и смешно говорить, что противоречие нельзя мыслить» [2, с. 206].

Уже в «Немецкой идеологии» К. Маркса и Ф. Энгельса - одной из первых работ, в которых появляются идеи коммунизма и революции, - выявляется группа противоречий, обусловливающих необходимость коренного изменения общества: бытие и сознание, производительные силы и состояние общества, духовная и материальная деятельность, наслаждение и труд, производство и потребление, частный и общий интерес. Разрешение противоречий в перспективе ведет к коммунизму: «Коммунизм для нас не состояние, которое должно быть установлено, не идеал, с которым должна сообразовываться действительность. Мы называем коммунизмом действительное движение, которое уничтожает теперешнее состояние» [3, с. 34].

Впоследствии в работах, относящихся к жанру исторического материализма, были систематизированы противоречия, представленные в трудах основоположников. Они были подробно описаны, выявлены взаимные связи. Набор противоречий внушителен: производительные силы и производственные отношения, вещественные и личностные составляющие производительных сил, базис и надстройка, общественное бытие и общественное сознание, общественная психология и общественная идеология, народные массы и личность, объективная необходимость и сознательная деятельность и др. На одном из первых мест стояло противоречие между классами. В рамках каждого из указанных противоречий отношение противоположностей может быть охарактеризовано гегелевской категорией своего иного. Не исключено, что именно от Гегеля советская политическая идеология унаследовала предрасположенность к оксюморонным формам, таким как демократический централизм.

Примером критики революционной теории, восходящей к гегелевской диалектике, служат труды основоположников анархизма. М. А. Бакунин дает оценку гегелевской диалектике. По его мнению, Гегель завершил построение абстрактного, чуждого жизни мира, создаваемого немецкой философией. «Окончательным завершением этого высокоидеального мира была философия Гегеля. Она вполне выразила и объяснила его своими метафизическими построениями и категориями и тем самым убила его, придя путем железной логики к окончательному сознанию его и своей собственной бесконечной несостоятельности, недействительности и, говоря проще, пустоты» [4, с. 432].

М. А. Бакунин утверждал, что «...гг. Бюхнер, Маркс и другие не умели и не умеют освободиться от преобладания метафизической абстрактной мысли» [4, с. 433]. Далее, выясняется, что «метафизики или позитивисты ...рыцари науки и мысли... считают себя призванными предписывать законы жизни...» [4, с. 435]. Возражение М. А. Бакунина весьма своеобразно: в России на восемьдесят миллионов жителей насчитывается всего несколько сотен ученых. Если же наука должна предписывать законы жизни, то огромное большинство, миллионы людей должны быть управляемы одной или двумя сотнями ученых. К тому же из всех наук управлению обществом учит только социология, а настоящих социологов в России и Европе не более двадцатитридцати. И они должны управлять целым миром? К тому же они, скорее всего, перегрызутся между собой, а если вдруг объединятся, то ничего хорошего из этого не получится. «Ученый уже по своему существу склонен ко всякому умственному и нравственному разврату...» [4, с. 435] Главная особенность разврата состоит в возвышении своего знания над действительностью, тогда как живой конкретноразумный ход разума - от действительного факта к мысли, его объясняющей [4, с. 434]. Если же это так, то встает вопрос: почему же позитивисты оказались в кампании метафизиков?

От факта к мысли пошел другой основоположник анархизма - Пётр Кропоткин. Материалом своих трудов он содержательно возражает против распространенного понимания борьбы противоположностей как подавления, понимания, которое, как считалось уже во времена Маркса, подкреплено, в числе прочего, естественно-научной идеей борьбы за существование, не порожденной умозрением, но имеющей прочную фактическую основу. Ход суждений П. А. Кропоткина направлен от взаимоотношений в животном мире к нравственным воззрениям племен первобытного типа, а затем - к необходимости анархического преобразования современного общества.

Согласно Бэкону, Огюсту Конту и Дарвину, «у стадноживущих животных вследствие их стадной жизни так сильно развивается общественный инстинкт, что он становится постоянно присущим инстинктом, до того сильным, что он берет верх даже над инстинктом самосохранения» [5, с. 434]. Оказывается, что «нравственное начало в человеке есть не что иное, как дальнейшее развитие инстинкта общительности, свойственного почти всем живым существам и наблюдаемого во всей живой природе» [5, с. 434].

«Изучая уцелевшие еще первобытные человеческие сообщества, мы находим, что в них продолжают развиваться те же нравы общительности. Мало того, по мере изучения мы открываем у них целый ряд обычаев и нравов, обуздывающих своеволие и устанавливающих начало равноправия» [5, с. 437]. П. А. Кропоткин выделяет три элемента нравственности: инстинкт общительности; понятие о справедливости; альтруизм. Справедливость требует не делать другим, чего не желаешь себе, а сущностью этого принципа становится признание равноценности и равноправия всех 
членов сообщества [5, с. 437]. Идея равноценности и равноправия, примененная к современному обществу, вполне естественно и логично приводит к отрицанию государства. Следует отметить, что П. А. Кропоткин был выдающимся географом, участвовал в сибирских экспедициях (кроме того - автор теории горообразования), с жизнью сибирских народностей был знаком не понаслышке.

Гегелевская диалектика, тем не менее, «пробивается» даже в сообщество анархистов, способных ее так или иначе осмыслить, интерпретируется в духе анархизма, что побуждает марксистов ответить на попытки ее анархистских интерпретаций и критики. В этом плане представляет интерес работа И. В. Сталина «Анархизм или социализм?», работа, что называется, «ранняя», подписанная «Коба». Она примечательна не столько критикой анархизма, сколько трактовкой диалектики.

Сталин констатирует, что марксизм есть цельное мировоззрение, философская система, именуемая диалектическим материализмом: метод - диалектический, теория - материалистическая. В философии диалектического материализма И. В. Сталин выделяет ключевые идеи.

Общественная жизнь изменяется. В ней всегда есть новое и старое, растущее и умирающее. Отсюда вытекает вопрос о направлении изменений. Оказывается, что растущее неодолимо. Сегодня рождается пролетариат. Хотя сегодня он слаб и малочислен, он растет, усиливается, идет вперед. В силу своего роста он победит. Буржуазия сильна сегодня, но она стареет, а потому обречена на поражение. Далее, следует комментарий к гегелевскому тезису, по поводу которого, возможно, было сломано наибольшее число копий: о разумности действительного. «...Всё то, что действительно существует, т. е. всё то, что изо дня в день растет, - разумно, а всё то, что изо дня в день разлагается, - неразумно и, стало быть, не избегнет поражения» [6, с. 299]. Получается, что всё растущее непременно победит, а устаревшее потерпит поражение. Исторический оптимизм торжествует.

Приводится пример дискуссии с народниками, которые утверждали, что освобождение России несет мелкая буржуазия деревни и города, поскольку она составляет большинство населения и живет в бедности. Ответ Сталина (от имени марксистов) состоит в том, что она как класс не растет, а разлагается и распадается на буржуа и пролетариев. Здесь совершенно явно преувеличено ожидание распада сельского населения на кулаков и наемных работников, но логика та же самая: победит растущее. Пролетариат — единственный растущий, по-настоящему прогрессивный класс.

Поднимается тема количественных и качественных изменений. Эволюция предшествует революции и готовит для нее почву. Идея качественных изменений подкрепляется примерами из области неживой и живой природы.

Следуют выводы относительно анархизма: 1) они знают и не устают повторять, что Гегель был консерватором; 2) разумеется, был, но это не опровергает революционности его диалектики. Паскаль, Лейбниц, Ламарк, Дарвин тоже не были революционерами, но это не помешало революционности их идей. Далее, следует дискуссия о противостоянии диалектики и метафизики, основная идея которой известна всей совокупности бывших советских философов по работе В. И. Ленина «К вопросу о диалектике».

Диалектическая традиция, идущая, упрощенно говоря, от Гераклита к Гегелю, не единственная версия диалектики. Р. Нейсбит своей работой «Географрия мысли» погружает нас в мир восточной диалектики, прежде всего — китайской. Творцом и носителем стихийной диалектики оказывается китайский крестьянин.

Оказывается, что западный индивид, решая какую-либо задачу, склонен руководствоваться формальной логикой. «Для азиата мир гораздо сложнее, а понимание явлений требует учета множества факторов с нелинейными межфакторными взаимодействиями. Формальная логика почти не применяется им для решения проблем. Более того, приверженца логики он склонен считать незрелым» [7, с. 18]. Китайцы не слишком интересовались вопросами управления — как людьми, так и природой. Значительно больше их занимал самоконтроль, который позволял минимизировать трения между членами семьи или деревни. В древнем Китае не было аналога греческому чувству личной воли. «Права личности в Китае - это лишь доля прав коллектива, а не разрешение поступать как заблагорассудится» [7, с. 33].

Принципиальные различия обнаруживаются в философии Греции и Китая. Для Аристотеля основной категорией, характеризующей объект, была сущность - неизменное индивидуальное бытие. Греки были склонны изучать объект сам по себе, как если бы он был выделен из среды. Мир они видели преимущественно статичным. Гераклит с его рекой, в которую не входят дважды, был исключением. Философия Китая (независимо от конкретных направлений) исходит из того, что всё в мире взаимосвязано. Согласно китайскому мироотношению всё окружающее нераздельно. Греки изобрели природу как «всё» кроме человека и культуры. Это означает, что объективность — производное от субъективности. У китайцев аналогичного европейской «природе» понятия просто не существует. Р. Нейсбит характеризует Гераклита Эфесского как философа с «почти восточными» взглядами. В Китае же был Мо-цзы - почти западный философ. Как говорится, в семье не без урода.

В дальнейшем западная и восточная культуры в течение длительного времени шли каждая своим путем. В средневековых европейских городах развивалось подобие демократического правления, что сопровождалось усилением индивидуализма. Впоследствии именно на западе обнаружилась тенденция к разделению любой деятельности на узкие стандартизированные операции. Восток с течением времени был вынужден его скопировать. Стоит добавить - весьма успешно и совсем даже не к радости запада.

Разница в отношении к миру имеет глубокие корни. Согласно Р. Нейсбиту, «в восточной философии, берущей начало в Древнем Китае, существует так называемый диалектический стиль мышления, концентрирующийся на противоречиях - на том, как решить или превзойти их, а может, найти зерно истины в каждом из взглядов» [7, с. 210]. Возможно, решительное определение «так называемой» диалектики как особенности чисто восточного мышления способно вызвать не вполне позитивное отношение не-вос- 
точного читателя, воспитанного на традиции, ведущей от Гераклита к Гегелю и далее, но позиция автора заслуживает внимательного отношения. Далее, следует конкретизация в виде трех принципов. Принцип перемен не нуждается в комментариях. Принцип противоречивости - следствие первого принципа: поскольку мир постоянно движется, в нем иной раз возникают парадоксы, противоречия, аномалии. Добро для своего понимания «нуждается» в зле и проч. Принцип всеобщей связности гласит, что всякая вещь связана с другими вещами. Чтобы что-то постичь, надо знать об отношениях вокруг него.

Возвращаясь к «первоисточнику», субъекту - носителю восточной диалектики - китайскому крестьянину, примем в качестве выводов следующее.

1. В ней присутствуют принципы развития и всеобщей связи, как и в западной диалектике, но, возможно, они глубже, чем на западе, укоренены в обыденном мироотношении. Результат какого-либо процесса - желательный или нежелательный, нельзя считать окончательным. Всё течет и меняется. Никакая вещь не имеет жестких очертаний, она может быть воспринята только во взаимодействии со средой. Природная среда, отношения в сельском «коллективе», власть, цели которой крестьянину непонятны, не дают возможности видеть мир в четких очертаниях.

2. Противоречия - вовсе не источник развития, они представлены или конфрликтами интересов в сельской среде, или же опасностями, приходящими извне - от власти или же из других внешних сил. Чтобы сколько-то успешно противостоять внешним силам, внутренние противоречия следует по возможности быстро и мирно разрешать. Таким образом, восточная диалектика, с одной стороны, вытекает из реалий обыденной жизни, с другой, является «методическим принципом», позволяющим ее по возможности упорядочить.

Обратимся еще к одной сфере жизни общества, не слишком прямо связанной с идеями справедливого общества и образом жизни китайских крестьян - к военному делу, представленному в работах А. А. Свечина - одного из виднейших отечественных военных теоретиков, не понаслышке знакомых и с военной практикой. Александр Андреевич был расстрелян в 1938 г. как враг народа, но его базисные идеи были реализованы и помогли победить в Великой Отечественной войне.

А. А. Свечин - знаток и горячий сторонник диалектики, базисные принципы которой он применяет к осмыслению военного дела. Принцип всеобщей связи в его трудах играет всеми красками. Промышленность, связь и транспорт, политика, разведка, информационная война, наконец, собственно война образуют единый комплекс. Ярким примером может служить его критика «пинкертоновских» методов в разведке вроде копирования (с риском для жизни) секретного документа во вражеском штабе. Располагая опытом работы в генеральном штабе во время Первой мировой войны, он констатирует, что в любом штабе издается множество документов, в том числе секретных, из которых ровно ничего не следует. Гораздо больше и красноречивее говорят о поведении будущего противника другие факты, которые не прячут в бронированных сейфах: концентрация заводов определенного профиля в определенных местах, строительство новых дорог и улучшение имеющихся, изменение тональности политических статей в общедоступных газетах, новые веяния во внутренней и внешней политике.

Относительно принципа развития А. А. Свечин решительно выступает против копирования прошлого опыта. Всё меняется, В том числе и методы ведения войны. В частности, он возражает против попыток подражания наполеоновской стратегии, которая сводилась к уничтожению вражеской армии в генеральном сражении и последующем занятии столицы. Отдавая должное военной гениальности Наполеона, он акцентирует изменение характера войн, так, что в современной войне ключевым фактором нередко становится процесс накопления сил и средств, в итоге приводящий к победе [8].

Убежденный диалектик, А. А. Свечин почти ничего не пишет о ее «ядре» - принципе противоречия. Возможно, что «невнимание» вполне оправданно, как и в предыдущем случае. Китайский крестьянин не мог узнать что-либо о том, какие глобальные и глубинные противоречия несут беду в его деревню. В военном же деле противоречие не приходится искать в сущностных глубинах, оно здесь-теперь, представлено зримо и наглядно в военных столкновениях, а потому, в отличие от чистой науки, его выявление не составляет проблемы.

1. Энгельс Ф. Людвиг Фейербах и конец классической немецкой философии // Маркс К., Энгельс Ф. Соч. : в 30 т. 2-е изд. М. : Политиздат, 1961. Т. 21. С. 269-317.

2. Гегель Г. Энциклопедия философских наук. Часть 1. Логика // Соч. : в 14 т. М. ; Л. : Гос. изд-во, 1929. Т. 1. 367 с.

3. Маркс К., Энгельс Ф. Немецкая идеология // Соч. : в 30 т. 2-е изд. М. : Политиздат, 1955. Т. 3. С. 7-544.

4. Бакунин М. А. Государственность и анархия // Бакунин М. А. Философия. Социология. Политика. М. : Правда, 1989. С. 291-526.

5. Кропоткин П. А. Справедливость и нравственность // Кропоткин П. А. Анархия и нравственность. М. : АСТ, 2019. C. 423-460.

6. Сталин И. В. Анархизм или социализм? // Соч. : в 13 т. Т. 1. М. : ОГИЗ, Гос. изд-во полит. лит., 1949. С. 294-392.

7. Нейсбит Р. География мысли / пер. с англ. Н. Парфеновой. М. : Астрель, 2012. 285 с.

8. Свечин А. А. Стратегия. М. : Военный вестник, 1927. 265 c. URL: http://swetschin.narod.ru/books/Svechin_AA_Strategy.pdf (дата обращения: 25.08.2020).

() Федяев Д. М., Шаров А. С., 2020 